\begin{tabular}{|c|c|c|c|c|c|c|}
\hline & & & \multicolumn{2}{|c|}{ Community Survey Follow-up } & \multicolumn{2}{|c|}{$\begin{array}{c}\text { Healed Tuberculosis Register } \\
\text { Follow-up }\end{array}$} \\
\hline Year & & & $\begin{array}{l}\text { No. examined } \\
\text { each year }\end{array}$ & $\begin{array}{l}\text { No. with } \\
\text { Tuberculosis }\end{array}$ & $\begin{array}{l}\text { No. examined } \\
\text { each year }\end{array}$ & $\begin{array}{l}\text { No. with } \\
\text { Tuberculosis }\end{array}$ \\
\hline $\begin{array}{r}1966 \\
1967 \\
1968 \\
1969 \\
\text { Total Observation Years }\end{array}$ & $\begin{array}{l}\cdots \\
\cdots \\
\cdots \\
\cdots\end{array}$ & $\begin{array}{l}\cdots \\
\cdots \\
\cdots \\
\cdots\end{array}$ & $\begin{array}{r}320 \\
332 \\
331 \\
389 \\
1,372\end{array}$ & $\begin{array}{r}4 \\
6 \\
2 \\
1 \\
13\end{array}$ & $\begin{array}{l}1,272 \\
1,328 \\
1,325 \\
1,556 \\
5,481\end{array}$ & $\begin{array}{l}1 \\
2 \\
3 \\
0 \\
6\end{array}$ \\
\hline
\end{tabular}

vation years 13 patients $(1.0 \%)$ have developed active tuberculosis. For comparison, patients who have been treated previously for pulmonary tuberculosis, the majority having had a full standard course of antituberculous drugs and five years' follow up at the clinic, have been similarly followed. In 5,481 observation years there have been six reactivations of tuberculous disease $(0.01 \%)$.

These figures show clearly the great value of following untreated inactive tuberculous lesions and confirm the excellent control achieved by adequate antituberculous drug treatment. It could be argued that the community survey patients should have been given drug treatment. It is doubtful if it would have been possible to enlist the co-operation and adequately supervise such prophylaxis in persons who consider themselves fit.

The procedure for managing patients with inactive untreated pulmonary tuberculosis varies greatly between clinics. In some the patients are assessed and dismissed from follow-up, others are diligently followed by regular clinic attendance, and some few receive antituberculous drugs. Our results show that both groups of patients may be followed up by $70 \mathrm{~mm}$. M.M.R. without serious risk of the disease breaking down between the annual visit. In only one instance did a patient, who had had inadequate drug therapy, break down in the intervening period and infect her husband and child. In two recent community chest $x$ ray surveys in the Borough of Ipswich, in which 7,372 adults over 14 years were $x$ rayed, over $1.2 \%$ showed just such lesions.

The lesson to be learnt from this and other similar experiences ${ }^{2}$ is that all apparently healed tuberculous lesions must be followed, no matter from where they originate, and mass chest $x$-ray is a good way of finding and following them.-I am etc.,

St. Helen's Hospital,
Ipswich.

Charles J. Stewart.

REFERENCES

Department of Health and Social Security. Mass Miniature Radiography Service, H.M. (69) 97 London, 1969. Styblo, K., et al., Bulletin of the World Health
Organization, 1967, 37, 819 .

\title{
Driving and Epilepsy
}

SIR,-You report (15 August, p. 362) that from 1 June 1970 new regulations for the issue of driving licences allow some people suffering from epilepsy to hold a driving licence. Such a person who suffers from epilepsy and who wants to drive must satisfy three conditions, one of which is that he has been free of an attack while awake for at least three years. No distinction is made between idiopathic and symptomatic epilepsy. The limited interval of three years may well be hazardous as the following patients in my practice during the past 15 years amply illustrate.

A man aged 40 years was discharged from the R.A.F. in 1949 suffering from epileptiform attacks. Phenobarbitone was started and he continued to take this drug until 1954, when it was finally stopped. He had been fit-free during this time. In November 1955 he had a major fit while golfing. Phenobarbitone was restart d an continued until 1962. He applied for and was granted a driving licence. $\mathrm{He}$ has driven daily since. In November 1966 he collapsed in status while walking to his car, his only fit during the preceding 12 years. $\mathrm{Ph} \sim$ nobarbitone has been restarted and he remains fit-free.

A man aged 23 suffered frequent major fits during childhood and until 1960. He was then controlled with phenobarbitone and phenytoin and he remained fit-free until he left school and started to work. By 1968 his phenobarbitone had been reduced to a nightly dose. He applied for a driving licence and was rcferred to a neurologist, who found no clinical evidence of epilepsy but subsequent E.E.G., though for the greater part normal, showed occasional bursts of instability which became suggestive of epileptiform pattern on overbreathing. He was advised to reapply in a further two years and meanwhile to continue phenobarbitone at night. In 1969 he developed several major fits while travelling to work, his first for nine years.

A man aged 44 years suffered from oscasional major fits until 1953, when primidone was prescribed. He apparently had k pt his driving licence because in 1962 after being free of majo fits for six years he developed a convulsive attack while driving and an accident resulted. His driving licence was withdrawn and E.E.G. the following year was normal. He continues to take primidone and has remained free of attacks since, but repeat E.E.G. in 1966 showed some epileptic features.

A man aged 43 was injured in 1951, when cylinder exploded, damaging his skull and left temporal area of brain. After elevation of skull fragments and excision of damaged train he made an unexpectedly good recovery. He remained phasic for some months but had no other residual neurological deficit. A few minor $f$ ts occurred in 1952 and he was start d on phenobarbitone, which by 1955 he discontinued. He applied for a driving licence in 1959, and was examined by a neurologist, who found no evidence of disease and his licence was granted. $\mathrm{He}$ has driven daily since. After some prolonged work in 1969 he collapsed in status epilcpticus as he walked from his car. He had been free of majo epileptic attacks for 14 years.

A man aged 52 years had occasional maior fits and took phenobarbitone unt 1 1953, when he discontinued the drug. He remained well until in 1958 he was crushed by a bus and his attacks returned. Phenobarbitone was restarted and apart from a doubtful minor episode in 1963 he remained well and phenobarbitone had been reduced to grain $\frac{1}{2}(30 \mathrm{mg}$.) at night. He applied for a driving licence and did not disclose to the ncurologist who examined him that he was st ll taking phenobarbitonc. The E.E.G. was stated to be normal and he had no other abnormal C.N.S. signs. The neurologist considered him to be fit to hold a driving licence. In 1968 he had a major fit after an interval of at least five and probably eight years.

Clearly, the statutory requirement that an epileptic who wishes to apply for a driving licence "be free from any major epileptic attack while awake during the preceding three years" is not necessarily adequate to ensure the safety of other road users.-I am, etc.,

Atherstone,
Warwicks.

K. T. FARN.

\section{Diabetes and the Driving Licence}

SIR,-Arising out of the recent regulations and the correspondence concerning epilepsy and the driving licence, one wonders what advice to give to diabetics when they apply for a licence.

The question to be answered is: "Are you suffering from any other disease or disability likely to cause the driving of a motor vehicle by you to be a source of danger to the public? If you are in doubt about your answers you should get professional advice."

My advice to well-controlled diabetics, who are not subject to hyperglycaemic or hypoglycaemic attacks, has been to answer: "No." Also I have not advised them to disclose that they suffer from diabetes to their motor insurance societies, unless specifically asked.

I would be grateful for the experience and opinions of other doctors on what advice they give their patients. Obviously there must be some diabetics who should answer "Yes," but I do not feel that all should be obliged to declare their disability. The most potentially dangerous cases must be the undiagnosed and untreated diabetics.-I am, etc.,

Wallington, Surrey. PATRICK J. O'ConNELl.

\section{Paraquat Toxicity}

SIR,- - It was sad that in paying tribute at the passing of Dr. Otto Warburg Drs. D. M. Stokes and D. A. Walker (22 August, p. 462) should draw attention to his theory on the origin of cancer cells which has little experimental support. The many inaccuracies of fact in the "evidence" they put forward confirm indeed their statement that they are not qualified to comment.

Reference to the literature would have shown that diquat does not cause "proliferation of the epithelium of the lung." After ingestion of paraquat (for which they evidently did not realize methyl viologen is merely another name) it is proliferation of fibroblasts, not epithelium in the lung, which is the striking pathological feature of the lesion. Proliferation of epithelium only occurs in terminal bronchioles and is probably a secondary phenomenon since it is found in other types of fibrosis involving this region of the lung. The fibroblastic reaction has none of the features of a cancerous process, and prolonged experiments in several animal species have failed to show any carcinogenic action of paraquat. This is accepted by the medical authorities in more 
than a hundred countries where paraquat is now used, most of which have strict regulations governing the use of pesticides.

In cases of human poisoning by paraquat, and in experimental animals, the highest concentrations are found in the kidneys and liver and though these organs show signs of damage there is no subsequent proliferation of any of their component cells. It would be expected that were induction of "near anaerobic conditions" a cause of the cellular reaction these organs would show more proliferation than the lungs. Measurement of ATP concentrations in paraquat poisoned animals also shows no change. There is therefore no parallel between Warburg's theory of carcinogenesis and the actions of paraquat as Drs. Stokes and Walker suggest.-We are, etc.,

\section{K. Fletcher}

Industrial Hygiene

Research Lab
I.C.I. Ltd

C.I. Ltd,

A. A. B. SWAN

Macclesfield, Cheshire.

REFERENCE Canning, D. M., Fletcher, K., and Swan, A. A. B.,
British Medical Bulletin, 1969, 5, 245.

SIR,-In their letter (22 August, p. 462) Drs. D. M. Stokes and D. A. Walker state that it is well established that poisoning by both paraquat and diquat is characterized by proliferation of the epithelium of the lung. The papers they quote refer only to cases of paraquat poisoning. As far as I am aware D. G. Oreopoulos and $\mathrm{I}^{\mathrm{I}}$ described the only case of diquat poisoning published to date, and there was no evidence of any lung lesion in this patient who recovered completely.-I am, etc.,

J. McEvoy.

Renal Unit,

Belfast City Hospital, Belfast.

\section{REFERENCE} Oreopoulos, D. G., and McEvoy, J., Postgraduate
Medical fournal, 1970, 45, 635.

\section{Undiagnosed Abdominal Pain}

SIR,-In your leading article entitled "Undiagnosed Abdominal Pain" (22 August, p. 415) you refer to Howie's suggestion "that the place of planned appendicectomy for mild or recurrent iliac fossa pain is a very restricted one,"l but quote figures from Ingram and Evans? showing that $90 \%$ of young women who had had diseased appendices removed were satisfied with the result, whereas only $45 \%$ with normal appendices had been satisfied post-operatively. Thus one needs some indication of those patients in whom recurrent pain in the right iliac fossa is, in fact, likely to be due to appendicular disease.

A few years ago I described a simple radiological method of demonstrating appendices using a barium mixture which contains a cellulose preparation (Raybar 75Damancy). ${ }^{3}$ By this method presumptive diagnosis can be made of an appendix which has suffered recurrent attacks of inflammation, so that unnecessary (and sometimes harmful) operations can be avoided. At the same time, in most cases, the terminal ileum and caecum are also well shown, so that other causes of the pain such as regional ileitis, may be revealed.

Follow-up in this series showed an $85^{\circ}$. improvement rate in those operated on which corresponds closely with Ingram and Evans's figures. Furthermore, since only a limited number of films are taken with as little screening as possible, the amount of radiation is kept to a minimum.-I am, etc.,

\section{MYeR GOLdMAN.}

$$
\begin{aligned}
& X \text {-ray Department, } \\
& \text { Fazakerley Hospi } \\
& \text { Liverpool. }
\end{aligned}
$$

REFERENCES

Howic, J. G. R., Lancet, 1968, 1, 1365

In ram, P. W., and Evans, G., British Medical

Golíman, M., Clinical Radiology, 1966, 17, 289.

\section{Breast-milk Jaundice}

SIR,-Y Your leading article (25 July, p. 178) comments that breast-milk jaundice is a complex problem. I wish to report certain aspects of the laboratory diagnosis of this condition which increase the complexity still further.

The inhibitory activity of human breast milk was evamined by determining its effect on the conjugation of bilirubin by male rat liver slices. ${ }^{1}$ Breast milk $0.2 \mathrm{ml}$. was added in a final incubation medium volume $3 \mathrm{ml}$. Using this technique I have examined milk from 163 nursing mothers, including 10 specimens from mothers of babies in whom a clinical diagnosis of breast-milk jaundice had been made. Most of the specimens were examined within one week of collection. This is essential since specimens kept at $-12^{\circ} \mathrm{C}$. increase their inhibitory aztivity toward conjugation in rat liver. This was examined by retesting 17 control breast milks for inhibitory activity against bilirubin conjugation in rat liver slices after keeping for 16 weeks at $-12^{\circ} \mathrm{C}$. All the milks showed an increase of inhibitory activity, the mean increase being $20.3 \%$. A number of breast milks have been further tested serially for inhibitory activity against bilirubin conjugation in rat liver slices. The results obtained with a representative breast milk are shown in the Table. The milk was kept at $-12^{\circ} \mathrm{C}$. after the first analysis.

\begin{tabular}{|c|c}
$\begin{array}{c}\text { Age of } \\
\text { Specimen }\end{array}$ & $\begin{array}{c}\text { Inhibitory Activity } \\
\text { (\% Inhibition of } \\
\text { Bilirubin Conjugation) }\end{array}$ \\
\hline $\begin{array}{c}8 \text { hours } \\
6 \text { Jays }\end{array}$ \\
12 ", & +5 \\
20 ", & 14 \\
$54, "$ & 7 \\
64, & 38 \\
\hline
\end{tabular}

Each result is a mean of duplicate analyses.

This observation has practical implications in that sterilized deep-frozen breast milk is used for feeding premature infants. Sterilized breast milks from a bank have been serially tested, but in the specimens tested therc was no development of inhibitory activity. It is possible that sterilization prevents the development of inhibition but this has not yet been fully investigated.

Another puzzling factor has been the high incidence of inhibitory activity toward bilirubin conjugation in milk from the control mothers. In the 153 control milks eight gave $100 \%$ inhibition of bilirubin conjugation in rat liver slices although the infants of these mothers were not sufficiently jaun diced to warrant serum bilirubin analyses. Complete inhibition of conjugation also occurred when these milks were added to other conjugation test systems. Preliminary experiments have shown that this inhibitory milk has an effect on conjugation similar to milk from mothers of infants with breastmilk jaundice.

These problems are being investigated further but give support to your observation that this is a very complex problem and may depend on infant susceptibility as well as secretion of inhibitory su'stances in maternal milk.

I thank my colleagues for referring specimens to me and the South-western Reg onal Hospital Board for financial assistance.-I am, etc., TOM HaRgREAVES Arca Department of Pathology,
Exeter, Devon.

\section{REFERENCE}

Lathe, G. $\mathrm{H}_{\text {., }}$ and Walker, M.. Biochemical

\section{Unified Filing System}

SIR,-Referring to the proposal made (1 August, p. 277) it may be pointed out that the numerical date indication given as example, with the sequence day, month, year, runs counter to the proposed British Standard (in draft as BSI doc. 70/4476) on "Rules for Writing Calendar Dates," which states "An all-numerical date shall be written in the following order: year-monthday."-I am, etc.

$$
\begin{aligned}
& \text { Chester, } \\
& \text { Cheshire. }
\end{aligned}
$$

V. BISKE.

\section{Acute Epiglottitis}

SIR,-Acute epiglottitis, a fulminating and often a fatal infection in young children, is infrequently recognized. In view of the laryngeal obstruction, urgent and specific treatment is required. Only few cases have been reported (Dr. J. D. Andrew and others 31 August 1968, p. 524), but probably many more go unrecognized. In view of a need for the widespread awareness of this condition it may be useful to report the following case.

A two-month-old baby girl was admitted to hospital on 21 September 1968 with increasing respiratory stridor and slight cyanosis. She looked ill, had a marked respiratory stridor with prominent substernal recession, and her temperature was raised to $100^{\circ} \mathrm{F}$. $\left(38^{\circ} \mathrm{C}\right.$.). Clinically and radiologically her chest was clear, laryngoscopy showed supraglottic oedema. The epiglottis was inflamed and oedematous and more or less occluding the glottic opening. A Jackson Rees nasoendotracheal tube was passed to establish a clear airway. The tube was left in for two days while the infection was controlled 